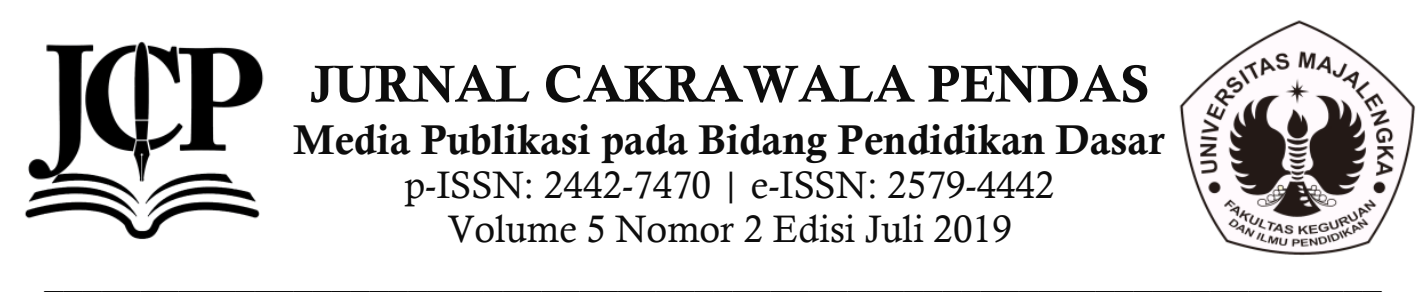

\title{
Pengaruh Membaca 15 Menit Terhadap Minat Baca Siswa Sekolah Dasar
}

\author{
Laela Safitri ${ }^{1}$, Aji Heru Muslim ${ }^{2}$,Santhy Hawanti ${ }^{3}$ \\ ${ }^{123}$ Universitas Muhammadiyah Purwokerto \\ 11ailasafitri674@gmail.com ${ }^{2}$ ajiherumuslim@gmail.com ${ }^{3}$ santhyhawanti.ump@gmail.com
}

\begin{abstract}
Abstrak
Kementerian Pendidikan dan Kebudayaan mencanangkan gerakan literasi sekolah (GLS) untuk menumbuhkan budaya membaca dan menulis siswa. Hal ini diperkuat dengan gerakan penumbuhan budi pekerti sebagaimana Peraturan menteri pendidikan dan kebudayaan Nomor 23 Tahun 2015. Gerakan Literasi Sekolah pada jenjang Sekolah Dasar dalam tahap pembiasaan yaitu membaca 15 menit buku non pelajaran sebelum waktu belajar dimulai. Tujuan penelitian ini yaitu mengetahui pengaruh membaca 15 menit sebelum pembelajaran terhadap minat baca siswa Sekolah Dasar. Metode yang digunakan yaitu korelasi sederhana. Subyek penelitian siswa kelas V di SD Negeri 1 Karanglewas Lor sebanyak 42 siswa. Instrumen yang digunakan yaitu tes dan non tes. Analisis data menggunakan SPSS statistik Versi 21. Berdasarkan SK nomor 421.2/ 25/2017 Gerakan Literasi Sekolah diterapkan di SD Negeri 1 Karanglewas Lor sejak tanggal 7 januari 2018. Hasil penelitian yang dilaksanakan pada tanggal 25 Maret 2019 menunjukan minat membaca siswa $16,7 \%$ berada pada kategori tinggi, $66,6 \%$ pada kategori sedang, dan $16,7 \%$ kategori rendah.
\end{abstract}

Kata kunci: Minat Membaca

\section{The effect of reading 15 minutes on reading interest in elementary school students}

\begin{abstract}
The Ministry of Education and Culture has launched a school literacy movement (GLS) to foster a culture of reading and writing students. This is supported by the growth movement that has been approved by Minister of Education and Culture Number 23 of 2015. GLS at the elementary level in habituating language is to read 15 minutes of textbooks before the lesson begins. The purpose of this study was to learn reading learning 15 minutes before learning to the reading interest of elementary students. The method used is a simple method. The research subjects of fifth grade students in SD Negeri 1 Karanglewas Lor were 42 students. The instruments used are tests and non-tests. Analysis of data using SPSS statistics Version 21. Based on Decree number 421.2 / 25/2017 GLS applied at SDN 1 Karanglewas since January 7, 2018. The results of the study conducted on March 25, 2019 showed students' interest in reading $16.7 \%$ depending on the high category, $66.6 \%$ in the medium category, and $16.7 \%$ in the low category.
\end{abstract}

Keywords: Reading Interest 


\section{Pendahuluan}

Membaca merupakan salah satu kemampuan yang dibutuhkan dalam kehidupan manusia. Melalui membaca seseorang dapat memperoleh berbagai pengetahuan maupun informasi yang belum diketahui. Olasehinde, M.O, dkk. (2015: 194) "Reading is basic building block of learning while the reading is the philosophy of developing a progressive reading attitude". Olasehinde (2015: 195) menegaskan kembali bahwa membaca sangat penting untuk menambah informasi dan pemahaman serta memperbaiki diri : "Reading in allits variety is vital to becoming better informed. It helps us to have a better understanding of our selves as well as others".

Membaca merupakan salah satu dari empat keterampilan berbahasa yang mempunyai peranan penting dalam kehidupan berbahasa. Tarigan (2015 : 1) menyatakan bahwa keterampilan berbahasa dalam kurikulum di sekolah mencakup empat segi, yaitu (1)keterampilan menyimak/mendengarkan;(2) keterampilan berbicara; (3) keterampilan membaca; dan (4) keterampilan menulis. Slavin, R.E., dkk. (2017: 22), "Kunci terpenting menuju keberhasilan siswa dalam menguasai keterampilan membaca yaitu pengembangan kosakata, kemampuan berbahasa lisan, kecintaan terhadap buku, dan aktivitas membaca". Membaca merupakan salah satu kemampuan yang harus dimiliki setiap siswa di samping keterampilan yang lain.

Progress in International Reading Literacy Study (PIRLS) mengungkapkan hasil kajian tingkat literasi siswa SD di Indonesia tahun 2011 berada pada peringkat 41 dari 45 negara. Organization for Economic Cooperation and Development/ OECD dalam hal Programme for International Student Assessment (PISA) di tahun 2015 mengklaim siswa Indonesia berada pada tingkat ke 62 dengan skor 397 (skor rata-rata OECD 496) dengan jumlah peserta yaitu 72 Negara. Hal tersebut menunjukan rendahnya minat membaca siswa Indonesia.

Upaya pemerintah untuk memaksimalkan kemampuan literasi siswa yaitu dengan mengintegrasikan literasi dengan kurikulum pembelajaran melalui
Gerakan Literasi Sekolah (GLS). Pada tahun 2013 Kementerian Pendidikan dan Kebudayaan melalui peraturan Menteri nomor 23 tahun 2013 mencanangkan sebuah gerakan literasi sekolah untuk membantu siswa dalam menumbuhkan budaya membaca dan menulis di lingkungan sekolah. Gerakan Literasi Sekolah ini diperkuat dengan gerakan penumbuhan budi pekerti sebagaimana dituangkan dalam Peraturan Menteri Pendidikan dan Kebudayaan Nomor 23 Tahun 2015.

Faradina (2017: 61), menyatakan bahwa kegiatan dalam Gerakan Literasi Sekolah tahap pembiasaan pada jenjang SD yaitu membaca 15 menit buku non pelajaran sebelum waktu belajar dimulai. Kegiatan ini mengharuskan siswa membaca buku selama 15 menit setiap pagi sebelum dimulainya jam pelajaran. Buku yang dibaca ialah selain buku mata pelajaran Materi baca berisi nilai-nilai budi pekerti, berupa kearifan lokal, nasional, dan global yang disampaikan sesuai dengan perkembangan siswa SD.

Membaca 15 menit sama artinya dengan sustained silent reading. Program lainnya yang serupa adalah Reading Time, FVR (Free Voluntary Reading), Self Selected Reading (SSR), siswa dibebaskan dalam memilih bacaan yang disukainya. Kegiatan membaca dilakukan dalam jangka waktu 15 sampai 20 menit. Tujuan dari program ini adalah untuk meningkatkan minat membaca pada anak-anak, membangun motivasi intrinsik sehingga para siswa yang senang membaca tidak perlu lagi didorong untuk membaca.

Tujuan penelitian yaitu mengetahui sejauh mana program membaca 15 menit sebelum pembelajaran berpengaruh terhadap minat membaca siswa, terutama siswa kelas V Sekolah Dasar.

\section{Metode Penelitian}

Metode penelitan yang digunakan dalam penelitian ini adalah kuantitatif dengan teknik korelasi sederhana. Sugiyono (2016: 45), untuk mencari besarnya pengaruh antara $\mathrm{X}$ dengan $\mathrm{Y} 1$, dan $\mathrm{X}$ dengan Y2 digunakan teknik korelasi sederhana. Teknik ini digunakan karena dalam penelitian ini berusaha mengetahui 
seberapa besar pengaruh program membaca 15 menit sebelum pembelajaran terhadap minat membaca dan kemampuan membaca pemahaman siswa kelas V Sekolah Dasar.

Sugiyono (2016: 80), populasi adalah wilayah generalisasi yang terdiri dari objek/subjek yang mempunyai kualitas dan karakteristik yang ditetapkan oleh peneliti untuk dipelajari. Populasi dalam penelitian ini adalah siswa kelas V Sekolah Dasar Negeri 1 Karanglewas Lor, Kecamatan Purwokerto Barat, Kabupaten Banyumas.

Teknik pengambilan sampel yang digunakan dalam penelitian ini adalah sampeling purposive, yaitu teknik penentuan sampel dengan pertimbangan tertentu (Sugiyono, 2016: 85). Sampel dalam penelitian ini yaitu siswa kelas V SDN 1 Karanglewas Lor yang berjumlah 42 siswa. Analisis data penelitian ini yaitu menentukan rentang nilai, $(\mathrm{R}=\mathrm{Xmax}-$ $\mathrm{Xmin})$, banyak kelas interval $(\mathrm{K}=1+3,3$ $\log \mathrm{n})$, menghitung standar deviasi (SD) dengan rumus:

$$
\mathrm{SD}=\frac{\sqrt{\sum f i(x i-\mathrm{x})^{n \cdot n-1}}}{\mathrm{n}-1}
$$

Menghitung presentase (p) rata-rata, dengan rumus:

$$
p=\frac{f}{N} \times 100 \%
$$

\section{Hasil Penelitian}

Untuk mengetahui pengaruh membaca 15 menit terhadap pemahaman dan minat baca siswa terlebih dahulu dilakukan uji coba instrumen penelitian. Uji coba instrumen dilakukan untuk mengetahui validitas dan reliabelitas instrumen penelitian sebelum disebarkan kepada sampel penelitian. Instrumen yang akan diuji yaitu angket minat baca dan tes pemahaman bacaan.

Uji coba intrumen angket diberikan kepada 42 responden diluar sampel penelitian. Dari 25 butir pernyataan isntrumen angket minat baca yang diujicobakan, sebanyak 20 butir pernyataan yang dinyatakan valid. Uji coba reliabilitas angkat minat membaca dihitung menggunakan rumus cronbach Alpha.

\begin{tabular}{|r|r|}
\hline $\begin{array}{c}\text { Cronbach's } \\
\text { Alpha }\end{array}$ & N of Items \\
\hline .706 & 21 \\
\hline
\end{tabular}

Berdasarkan rumus Alpha, perhitungan reliabilitas instrumen angket minat membaca diperoleh 0,706 dari 20 butir soal yang valid. Hal ini berarti instrumen minat membaca dinyatakan reliabel.

Program membaca 15 menit sebelum pembelajaran pada jenjang pendidikan Sekolah Dasar termasuk tahap pembiasaan dalam Gerakan Literasi Sekolah. SDN 1 Karanglewas Lor sudah menerapkan Gerakan Literasi Sekolah sejak tanggal 7 januari 2018, untuk lebih jelasnya dapat dilihat SK nomor 421.2/ 25/2017 yang terlampir. Adapun kegiatannya yaitu jadwal wajib kunjung perpustakaan, pemberdayaan mading tiap kelas, membaca buku non pelajaran sebelum proses belajar dimulai, posterisasi sekolah, dan membuat sudut baca di beberapa tempat di sekolah.

Program membaca 15 menit sebelum pembelajaran yang dilakukan di SDN 1 Karanglewas Lor selain membiaasakan siswa untuk membaca juga membiasakan siswa berbagi informasi yang diperoleh setelah membaca. Seperti tertera pada peraturan pelaksanaan pada lampiran 19 . Penelitian ini bermaksud untuk mengetahui seberapa besar pengaruh program membaca 15 menit sebelum pembelajaran yang telah berjalan sejak tanggal 7 Januari 2018 di SDN 1 Karanglewas Lor. Instrumen yang digunakan untuk mengetahui minat baca siswa yaitu menggunakan lembar angket minat membaca yang berisi 20 pernyataan. Pernyataan dalam angket meliputi aspek perasaan senang, pemusatan perhatian, penggunaan waktu, motivasi untuk membaca, emosi dalam membaca, dan usaha dalam membaca.

Data yang digunakan untuk mengungkap minat membaca siswa kelas $\mathrm{V}$ SDN 1 Karanglewas Lor yaitu angket skala likert yang dibagikan kepada 42 responden. Hasil analisis yang diperoleh menggunakan SPSS versi 21 sebagaimana berikut. 
Tabel 1 Distribusi Skor Nilai Statistik Minat Membaca

\begin{tabular}{lc}
\hline \multicolumn{1}{c}{ Statistik } & $\begin{array}{c}\text { Minat } \\
\text { Membaca }\end{array}$ \\
\hline $\begin{array}{l}\text { N (jumlah } \\
\text { siswa) }\end{array}$ & 42 \\
\hline Nilai maksimal & 94 \\
\hline Nilai minimal & 63 \\
\hline Mean & 79,40 \\
\hline Median & 80 \\
\hline Modus & 83 \\
\hline Standar Deviasi & 7,315 \\
\hline
\end{tabular}

Tabel 4.2 di atas menjelaskan bahwa data minat membaca diperoleh skor tertinggi 94 , skor terendah 63 , mean 79,40 , median 80, modus 83, dan standar deviasi 7,315 .

Hasil angket yang meliputi aspek perasaan senang, pemusatan perhatian, penggunaan waktu, motivasi untuk membaca, emosi dalam membaca, dan usaha dalam membaca di kelas V SDN 1 Karanglewas Lor adalah sebanyak 5 siswa $(12 \%)$ dalam kategori rendah, 31 siswa (74\%) dalam kategori sedang dan 6 siswa (14\%) dalam kategori tinggi. Kategori tingkat skor minat membaca siswa dapat dilihat pada gambar 4.1 berikut.

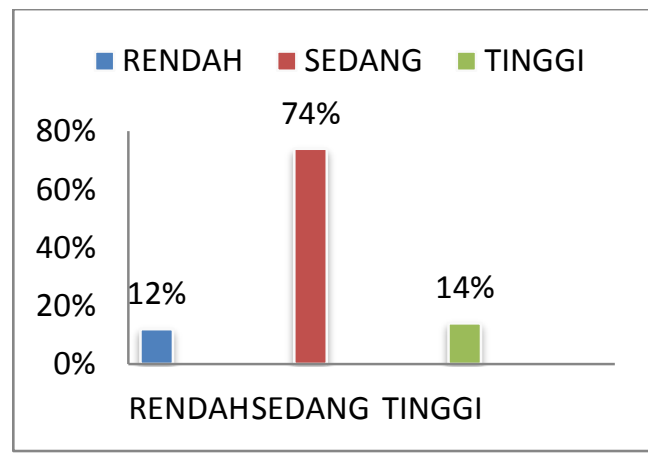

Gambar 1 Diagram Kategori Skor Minat Membaca

Menurut Hurlock (Dalman, 2017: 149150) ada lima faktor yang dapat mempengaruhi minat baca seseorang. Pada pembahasan ini peneliti fokus pada salah satu faktor yang mempengaruhi minat membaca seseorang, yaitu minat diperoleh dari budaya. Budaya yang diterapkan di SDN 1 Karanglewas Lor yaitu Program membaca 15 menit sebelum pembelajaran. Siswa diwajibkan membaca buku setiap hari selama 15 menit sebelum pelajaran pertama dimulai.

Berdasarkan hasil penelitian, dapat diketahui bahwa siswa kelas V SDN 1 Karanglewas Lor yang berjumlah 42 responden, skor tertinggi 78, skor minat membaca terendah 49 , mean atau rata-rata yaitu mean 64,64, median 64,50, modus 64 , dan standar deviasi 6,702. Tingkat minat membaca sebanyak sebanyak 7 siswa $(16,7 \%)$ dalam kategori rendah, 28 siswa $(66,6 \%)$ dalam kategori sedang dan 7 siswa $(16,7 \%)$ dalam kategori tinggi. Artinya, program membaca 15 menit sebelum pembelajaran memiliki pengaruh terhadap minat membaca siswa, dan ada faktor lain yang mempengaruhinya.

Minat baca yang tinggi sebesar $16,7 \%$ berdasarkan hasil penelitian ini dikarenakan siswa sudah terbiasa membaca buku setiap pagi sebelum pelajaran dimulai. Dibuktikan juga dengan perolehan skor pada lembar angket minat membaca nomor 12 yaitu sebesar 147 dari skor maksimal 168. Hal tersebut tentunya karena adanya program membaca 15 menit sebelum pembelajaran yang dilaksanakan setiap hari.

Minat membaca kategori sedang sebesar $66,6 \%$. Hal ini dapat terjadi karena siswa merasa senang membaca dan beranggapan bahwa kegiatan membaca bukanlah hal yang membuang-buang waktu. Siswa membaca karena untuk menambah ilmu. Dapat dilihat dari hasil angket nomor 1, 5, dan nomor 9 . Pernyataan ini selaras dengan penelitian oleh Anand S., Anand Y dan Kenchakkanavar tentang "Reading Habits by the Students of Karnataka Science College, Dharwad: A Study" (2015) yang menyatakan bahwa bahwa mayoritas 127 siswa (51,64\%) menikmati membaca, 79 (32,11\%) responden sangat menikmati membaca, 32 (13\%) responden menjawab hanya apa-apa dan selain kategori ini 8 (03.25\%) responden tidak menikmati membaca. Ini memperlihatkan bahwa Kebiasaan membaca di sana mempengaruhi minat baca ditunjukan dengan menikmati membaca.

Minat membaca kategori rendah sebesar $16,7 \%$ dikarenakan siswa jarang membaca buku ketika liburan. Minat seseorang akan tumbuh dengan adanya 
budaya atau kebiasaan yang terus menerus dilakukan hingga terbiasa. Usaha-usaha yang dilakukan SDN 1 Karanglewas Lor dalam membiasakan siswa gemar membaca yaitu dengan adanya Program Literasi Sekolah, khususnya pada kegiatan membaca 15 menit sebelum pembelajaran dimulai. Siswa dibiasakan untuk membaca setiap pagi. Nurhadi (2018: 2) mendefinisikan, membaca adalah kegiatan memahami makna yang terdapat dalam tulisan. Seseorang dapat mengetahui suatu informasi atau pesan melalui kegiatan memahami tulisan. Kegiatan membaca bukan hanya melihat kumpulan huruf saja, akan tetapi juga memahami makna yang terkandung.

\section{Kesimpulan}

Hasil penelitian menunjukan minat membaca siswa kelas V SDN 1 Karanglewas Lor $16,7 \%$ berada pada kategori tinggi karena siswa membaca buku setiap pagi sebelum pembelajaran selama 15 menit. Minat membaca $66,6 \%$ pada kategori sedang, karena siswa merasa senang saat membaca dan beranggapan membaca bukanlah kegiatan yang membuang-buang waktu. Siswa membaca untuk menambah ilmu. dan 16,7\% kategori rendah disebabkan karena siswa jarang membaca ketika liburan.

\section{Daftar Pustaka}

Dalman. 2017. Keterampilan Membaca. Jakarta: Rajawali Perss

Faradina, N. 2017. Pengaruh Program Gerakan Literasi Sekolah Terhadap Minat Baca Siswa di SD Islam Terpadu Muhammadiyah An-Najah Jatinom Klaten. Hanata Widya. 8 (6): 60-69

Kemendikbud. 2016. Panduan Gerakan Literasi Sekolah di Sekolah Dasar. Jakarta: Direktorat Jendral Pendidikan Dasar dan Menengah Kementerian Pendidikan dan Kebudayaan

Khairuddin, Z. 2013. A Study of Students' Reading Interest in a Second Language. International Education Studies. 11 (6):160-170
Medar, A.S., Anand, Y., dan Kenchakkavanar. 2015. Reading Habits by the Students of Karnataka Science College, Dharwad: A Study. International Research: Journal of Library \& Information Science. 3(5):384-394

Medar, A.S., Anand, Y., dan Kenchakkavanar. 2015. Reading Habits by the Students of Karnataka Science College, Dharwad: A Study. International Research: Journal of Library \& Information Science. 3 (5): 384-394

Musfiroh, T., \& Listyorini, B. 2016. Konstruk Kompetensi Literasi untuk Siswa Sekolah Dasar. LITERA. 1 (15): $1-12$

Nurhadi. 2018. Teknik Membaca. Jakarta: Bumi Aksara

Olasehinde, M.O., dkk. 2015. Promoting the Reading Culture towarrds Human Capital and Global Development. English Language Teaching. 6 (8): 194- 200

Robert, E. Slavin., dkk. 2017. Membaca Membuka Pintu Dunia: Program Success For All Model yang Jelas dan Kuat Untuk Meningkatkan Kemampuan Membaca Anak Sekolah Dasar. Yogyakarta: Pustaka Pelajar

Sugiyono. 2016. Metode Penelitian Kuantitatif, Kualitatif, dan $R \& D$. Bandung: Alfabeta

Sugiyono. 2016. Metode Penelitian Kuantitatif, Kualitatif, dan $R \& D$. Bandung: Alfabeta

Tarigan, H.G. 2015. Membaca Sebagai Suatu Keterampilan Berbahasa. Bandung: Angkasa 